\title{
CLINICAL STUDIES TO EVALUATE PEROXIDATIVE STRESS AND ANTIOXIDANT COMPLEMENT IN LIVER CANCER IN INDIAN AND HUNGARIAN SUBJECTS
}

\author{
SAMAR RAJENDRA KUMAR ${ }^{1}$, JAIN SUMAN ${ }^{2 *}$, SOGANI SONAL ${ }^{2}$
}

${ }^{1}$ Department of Medicine, Pacific Institute of Medical Sciences, Udaipur, Rajasthan, India. ${ }^{2}$ Department of Biochemistry, Pacific Institute of Medical Sciences, Udaipur, Rajasthan, India. Email: sumannemijain@gmail.com

Received: 26 December 2019, Revised and Accepted: 13 January 2020

\section{ABSTRACT}

Objective: Liver cancer is the leading cause of death due to malignancies all over the world. Free radical-induced oxidative stress extent can be provoked by antioxidant mechanisms decreased efficiency. The present study was carried out to investigate the extent of oxidative stress and the levels of antioxidants in the circulation of patients with liver cancer.

Methods: Plasma thiobarbituric acid reactive substances (TBARS) and level of some antioxidant enzymes as superoxide dismutase (SOD), catalase (CAT), glutathione peroxidase (GSH-Px), and GSH be determined in the circulations of 100 Indian and Hungarian patients with liver cancer and an equal number of age-matched normal subjects.

Results: Significantly increased concentrations of TBARS plasma levels and significantly lowered levels of SOD, CAT, GSH, and GSH-Px were observed in patients with liver cancer which may have occurred due to increased use to scavenge lipids peroxides as well as their sequestration by tumor cells. Increased lipid peroxidation in liver was seen which may be due to excessive oxidative stress. Comparison between Indians and Hungarians subjects revealed 200\% increased malondialdehyde levels in Hungarian male patients as compared to Indian male patients. SOD was found to decrease in Indian subjects whereas CAT (20\%) higher, GSH (25-35\%) less decrease GSH-Px (5\%) more decrease in Hungarians patients compared to Indian patients.

Keywords: Antioxidants, Peroxidative stress, Malondialdehyde, Superoxide dismutase, Catalase, Glutathione, Glutathione peroxidase.

(C) 2020 The Authors. Published by Innovare Academic Sciences Pvt Ltd. This is an open access article under the CC BY license (http://creativecommons. org/licenses/by/4. 0/) DOI: http://dx.doi.org/10.22159/ajpcr.2020.v13i3.36710

\section{INTRODUCTION}

It has been reported that globally in 1975, primary liver cancer was ranked seventh in men and by 1990, it reached the fifth ranking with a $73 \%$ increase in the burden [1]. As per the WHO, more than 622,000 people across the world died due to this fatal disease. The disease is highly related to Hepatitis B and C virus. The primary cause of this disease is exposure to these viruses; however, smoking and intake of liquor are also among one of the main reasons for liver cancer [2]. The position of oxidative damage in carcinogenesis is increasingly being valued. Free radicals are species capable of independent existence having one or more lone paired electrons in their outer most shell.

Environmental factors are the major cause of tumors which act almost always through free radicals. These are involved in both the initiation and promotion of multistage carcinogenesis by damaging DNA, resulting in mutation proto-oncogene activation and inactivation or loss of tumor suppressor gene [3]. Further oxidative stress has major role in the pathogenesis of toxic liver diseases and in some kind of hepatic alterations [4], an antioxidant is a substance which not only delays or prevents oxidation of substrates but also constitutes the body's primary defense against free radicals' injury. Oxidative stress reduction by providing antioxidants was optional as an effective option of chemoprevention [3]. Oxidative stress revealed by increased free radical generation or by decreased antioxidant level in the target cells and tissues plays an important role in carcinogenesis [5-7]. Free radicals' molecules levels are controlled by several cellular defense mechanisms comprising of enzymes catalase (CAT), superoxide dismutase (SOD), and glutathione (GSH) peroxidase plus GSH components [8]. The present study was undertaken to estimate the extent of oxidative stress by measuring thiobarbituric acid reactive substances (TBARS) and antioxidant parameters in serum and plasma of the patients suffering from liver carcinoma.

\section{METHODS}

The present research was conduct in Pacific Institute of Medical Sciences (PIMS), Umarda, Udaipur and Hospital-2 of Szeged, Hungary. Healthy subjects (100 Indian and 100 Hungarians) and 100 liver cancer patients from both India and Hungary (outdoor and indoor) were chosen for this study. A detailed history and present conditions of the selected subjects were recorded on a designed pro forma regarding their general information, including age, sex, height, weight, caste, religion, nutritional habits, and teaching. The usual subjects were healthy medical students, staff members, attendants with patients and donors of blood bank of PIMS, Umarda, Udaipur and of Hospital-2 of Szeged, Hungary.

\section{Biochemical estimations}

Lipid peroxide was determined by the measurement of TBARS in plasma by the method of Yagi [9]. The lipid peroxidation was estimated spectrophotometrically at $532 \mathrm{~nm}$. SOD was analyzed by the method of Kakkar et al. [10]. CAT activity was assayed by the technique of Sinha [11]. Hemolysate was treated with hydrogen peroxide $(0.2$ $\mathrm{mol} / \mathrm{L})$, the reaction was arrested after $60 \mathrm{~s}$ by the addition of dichromate - acetic acid reagent cooled and the intensity of color was deliberate at $620 \mathrm{~nm}$. Various aliquots of $\mathrm{H}_{2} \mathrm{O}_{2}$ be used as the standard. A system devoid of the enzyme serves as the control GSH and was assayed by the method of Beutler and Kelly (1963) and GSH peroxidase by Hopkins and Tudhope, 1973. The records for biochemical analysis are expressed as mean and standard deviation. The Student's t-test was used for statistical comparisons.

\section{RESULTS}

Height of lipid peroxidation in plasma of normal and of liver cancer patients is reported in Table 1. Lipid peroxidation as assayed by TBARS 
level was found significantly higher in liver carcinoma patients as compared to normal subjects. MDA levels showed rise in patients and were 5 times increase than Indian male patients. In Hungarians the level was two times higher in patients than Hungarian control subjects. The Hungarians control showed higher levels even than Indian controls.

The level of antioxidants in the flow of normal subjects and of liver cancer patients is reported in Tables 2 and 3. The enzymatic antioxidants as SOD were decreased in Indian patients as compared to Hungarian patient. In comparison to controls, Indians and Hungarians both showed increased levels, but the increase was found more in Hungarians. CATs in the hemolysate was about twice higher in Hungarian liver cancer patients as compared to Indian patients, but if we compare controls than levels in patients were lower than the levels in controls both in Indians and Hungarians. Furthermore, the non-enzymatic antioxidants GSH were less decreased in Hungarian patients than in Indian patients. Overall, Hungarian patients (both male and female) showed more decrease in glutathione peroxidase (GSH-Px) levels as compared to Indian patients (both male and female). The levels were more in Hungarian patients as compared to Indian patients.

\section{DISCUSSION}

In the examination of normal subjects of India and Hungary, Hungarians showed higher lipid peroxidation. Therefore, it was thought to germane a study in them for several reasons, although Caucasoid is a common factor, Hungarians do have some genetic differences from Indians, because of certain features which make them different from Indians such as: (a) Less populated atmosphere, (b) better nutrient intake,

Table 1: Lipid peroxidation (nmol of malondialdehyde formed ml of plasma): Comparison in Indian and Hungarians

\begin{tabular}{|c|c|c|c|c|}
\hline \multirow[t]{3}{*}{ Subjects } & \multicolumn{4}{|l|}{ Mean \pm SD } \\
\hline & \multicolumn{2}{|l|}{ Indians } & \multicolumn{2}{|l|}{ Hungarians } \\
\hline & $\begin{array}{l}\text { Males } \\
(n=58)\end{array}$ & $\begin{array}{l}\text { Females } \\
(n=42)\end{array}$ & $\begin{array}{l}\text { Males } \\
(n=64)\end{array}$ & $\begin{array}{l}\text { Females } \\
(n=36)\end{array}$ \\
\hline $\begin{array}{l}\text { Control } \\
(\mathrm{n}=100)\end{array}$ & $2.55 \pm 0.71$ & $2.25 \pm 0.56$ & $8.60 \pm 2.70$ & $7.10 \pm 0.62$ \\
\hline $\begin{array}{l}\text { Liver cancer } \\
(\mathrm{n}=100)\end{array}$ & $3.16 \pm 0.97$ & $3.64 \pm 1.00$ & $16.24 \pm 4.98$ & $17.26 \pm 2.38$ \\
\hline
\end{tabular}

SD: Standard deviation (c) use of tinned food is common for them, (d) regular habits of drinking alcoholic beverages, and (e) smoking habits.

All these factors influence oxidant status. Burn [11] and alcohol intake [12,13] increase peroxidative stress. The TBARS level in normal Hungarian males, females, was $8.60 \pm 2.70 \mathrm{nmol} / \mathrm{ml}$ and $7.10 \pm 0.62 \mathrm{nmol} / \mathrm{ml}$ and $2.25 \pm 0.56 \mathrm{nmol} / \mathrm{ml}$. Thus, TBARS level in Hungarians was about 3 times higher than Indians. This observation is very significant as it explicitly points out a higher oxidant burden in Hungarians [14]. As MDA is direct adduct of polyunsaturated fatty acids (PUFA), this is essential constituent of cellular membrane lipids and many other cellular components; therefore, three deductions can be complete; (a) membrane lipids are more damaged in Hungarians as compared to Indians, (b) PUFA located in other cellular or additional cellular compartment are more injured, and (c) else both are partly injured. It is important to note that damage need not be necessarily expressed in the form of pathology, because tissues are always in a condition of lively balance and possess an effective repair system. The data are of greater significance when viewed in context to the antioxidant status which is better in them. Four antioxidants were measured, namely, GSH, SOD, CAT, and GSH-Px. Interestingly, SOD and GSH levels were significantly higher and other tended to be higher in them than Indians. Clearly, the reason could be the need for better defense batteries. It is now we know that all the three enzymes are inducible enzymes and their activity in Hungarians innately implies that their induction should be to meet an improved generation of superoxide anion and free hydroxyl radical. Similarly, the increased level of GSH should meet the increased insist of GSH-Px.

It has been frequently pointed out in the literature that reduced GSH is a major endogenous antioxidant[15]. In the western population, the reported normal range is $47-80 \mathrm{mg} / 100 \mathrm{ml}$. In Hungarian males and females sits level was $67.10 \pm 7.30$ and $69.00 \pm 7.31$, respectively. These levels are clear signs of an adequate status. In Indian subjects, its level is reported to very wide extent. Our study found values comparable[16], but in others, it was found to be lower $[17,18]$. Green and Paller [15] discussed that potent exogenous sources of free radicals include oxidized drugs, smoke, radiations, and other substances. And also, that endogenous antioxidation GSH is preferentially oxidized to save tissues from disasters of oxidant injury. It is very well recognized that free radicals are the byproducts of metabolic processes and originate from environmental pollutant[16], where again GSH comes to rescue along with other antioxidants., Therefore, lower level of GSH in Indians represents

Table 2: Antioxidants levels in controls in Indian and Hungarian subjects

\begin{tabular}{|c|c|c|c|c|}
\hline \multirow[t]{3}{*}{ Parameters } & \multicolumn{4}{|l|}{ Mean \pm SD } \\
\hline & \multicolumn{2}{|l|}{ Indians } & \multicolumn{2}{|l|}{ Hungarians } \\
\hline & Males $(n=58)$ & Females $(n=42)$ & Males $(n=64)$ & Females $(n=36)$ \\
\hline SOD (U/mg Hb) & $3.86 \pm 0.69$ & $3.26 \pm 0.85$ & $1.32 \pm 0.40$ & $1.900 \pm 0.36$ \\
\hline Catalase $\left(\mu \mathrm{mol} \mathrm{H}_{2} \mathrm{O}_{2} / \mathrm{min} / \mathrm{mg}\right.$ protein $)$ & $87.98 \pm 15.36$ & $88.26 \pm 14.65$ & $94.80 \pm 27.60$ & $90.34 \pm 27.80$ \\
\hline $\mathrm{GSH}(\mathrm{mg} / \mathrm{dl})$ & $36.46 \pm 5.43$ & $35.00 \pm 15.43$ & $67.10 \pm 7.30$ & $69.00 \pm 7.30$ \\
\hline GSH-Px $\left(\mathrm{mg} \mathrm{GSH} /\right.$ minat $\left.37^{\circ} \mathrm{C}\right)$ & $2.36 \pm 1.02$ & $2.02 \pm 1.21$ & $9.11 \pm 0.65$ & $8.68 \pm 0.85$ \\
\hline
\end{tabular}

SOD: Superoxide dismutase, GSH-Px: Glutathione peroxidase, SD: Standard deviation

Table 3: Antioxidants levels in patients in Indian and Hungarian subjects

\begin{tabular}{|c|c|c|c|c|}
\hline \multirow[t]{3}{*}{ Parameters } & \multicolumn{4}{|l|}{ Mean \pm SD } \\
\hline & \multicolumn{2}{|l|}{ Indians } & \multicolumn{2}{|l|}{ Hungarians } \\
\hline & Males $(n=58)$ & Females $(n=42)$ & Males $(n=64)$ & Females $(n=36)$ \\
\hline SOD (U/mg Hb) & $3.96 \pm 2.68$ & $3.96 \pm 0.65$ & $11.99 \pm 0.46$ & $13.03 \pm 0.67$ \\
\hline Catalase $\left(\mu \mathrm{mol} \mathrm{H}_{2} \mathrm{O}_{2} / \mathrm{min} / \mathrm{mg}\right.$ protein $)$ & $64.06 \pm 18.24$ & $69.46 \pm 15.52$ & $78.98 \pm 16.87$ & $78.33 \pm 23.15$ \\
\hline $\mathrm{GSH}(\mathrm{mg} / \mathrm{dl})$ & $20.00 \pm 4.20$ & $20.84 \pm 15.50$ & $53.42 \pm 8.02$ & $58.00 \pm 8.72$ \\
\hline GSH-Px (mg GSH $/$ minat $\left.37^{\circ} \mathrm{C}\right)$ & $0.92 \pm 1.14$ & $0.86 \pm 1.14$ & $5.08 \pm 1.41$ & $5.81 \pm 1.01$ \\
\hline
\end{tabular}

SOD: Superoxide dismutase, GSH-Px: Glutathione peroxidase, SD: Standard deviation 
a discouraging picture about antioxidant status which is generally weak due to weaker nutritional antioxidant status.

Strikingly SOD levels were found senior in together Hungarian males $(1.32 \pm 0.40$ units $/ \mathrm{ml}$ hemolysate $)$ and females (1.91 \pm 0.36 units $/ \mathrm{ml}$ hemolysate). This is 3.4 and 5.82 times higher than the matching subject. This higher level can be due to a genetic consequence of an adaptive mechanism to meet improved flux of superoxide anion; the latter one appears more plausible.

Oxidative stress is the result of a disturbance in the balance between the production of ROS and the efficiency of the antioxidant defense[19]. Potential targets for free radical assault include lipids, proteins, and nucleic acids[20]. The epoxides generated because of increased oxidative stress may impulsively react with nucleophilic centers in the cell and thus covalently bind to DNA and RNA and protein. Such reactions may guide to cytotoxicity and carcinogenicity depending on the properties of the epoxides[21]. Moreover, severe oxidative pressure is not only known to cause genetic material and mutations in tumor suppressor genes but also for playing an important role in the promotion of multistep carcinogenesis $[14,15]$. Due to its far above the ground cytotoxicity and inhibitory action on defensive enzymes, the end product of lipid peroxidation MDA is optional to act as a tumor promoter and a cocarcinogenic agent [17]. The plasma of cervical growth patients is as well experiential for the increased lipid peroxidation[18]. In this present study, it was noticed that increased levels of circulating TBARS in liver cancer patients which can be accredited to the deficiency of antioxidant defense mechanisms.

In all cells, the antioxidant enzymes SOD and CAT are present in higher amounts in erythrocytes. SOD enzyme protects against $\mathrm{O}^{2-}$ by dismutation of the highly reactive superoxide anion to oxygen to a less reactive species to hydrogen peroxide [16] and CAT protects the cell from $\mathrm{H}_{2} \mathrm{O}_{2}$ [19]. In the present study, it has been experiential that low levels of SOD and CAT in liver cancer patients. This correlates with the increase in peroxidation activity. A decrease in the activity of CAT and SOD could be the result of an increase in lipid peroxidation products. MDA that forms a cross-link in activating several membranes bound enzymes and an increase in lipid peroxide could be a possible cause of decreased SOD levels. Decreased CAT could be due to the use of enzymes because of increased peroxidation. Antioxidant GSH-PX present in the cell along cell membrane [20], is a radical scavenge antioxidant [20], which is found in all cells as a reducing agent. A lipid peroxidation and its positive correlation with antioxidants have been documented. Many studies regarding ovarian and other cancers also show an inverse association between circulating levels of antioxidants [21]. Due to low economic status and habits of using less fruits and vegetables, people here are too thin and thus prone to malignancy and thus, associated with cancers and also with liver cancer[22].

\section{CONCLUSION}

A comparative study was taken on between healthy and liver cancer subjects with respect to lipid peroxidation and antioxidant level in Indians and Hungarians. MDA levels in healthy subjects $(2.55 \pm 0.71$ in males and 2.25 \pm 0.56 in females of Indian population whereas $8.60 \pm 2.70$ in males and $7.10 \pm 0.62$ in females in Hungarian population) and levels in patients $(3.16 \pm 0.97$ in males and $3.64 \pm 1.00$ in females in Indians whereas $16.24 \pm 4.98$ in males and $7.26 \pm 2.38$ in females). Hungarians were significantly higher than controls. SOD and CAT levels were lower in patients than healthy controls. GSH and GSH-Px were significantly lower in patients than in healthy controls.

\section{AKNOWLEGMENT}

We sincerely thank PIMS, Medical College and Associated Hospital, Udaipur, and Hospital-2, Szeged, Hungary, for extending all the facilities for conducting the research work. The authors also acknowledge the immense help received by the scholars whose articles are cited and included in references to this paper. The authors are also grateful to writers, editors, and publishers of all those articles, journals, and books from where the text for this article has been reviewed and discussed.

\section{AUTHORS' CONTRIBUTIONS}

The author declares that all the named authors have contributed equally to this article.

\section{CONFLICTS OF INTEREST}

The authors have no conflicts of interest to disclose.

\section{FUNDING}

This research did not receive any specific grant from funding agencies.

\section{REFERENCES}

1. Perin N. Global variation in cancer incidence and mortality. Curr Sci 2001;181:465.

2. New Hope for Liver Cancer Patients. $6^{\text {th }}$ ed. Newstract India; 2007.

3. Khanna K, Nikunji N, Khanna HD. A study of antioxidant and their preventive potential in cervical Dysplasia. Asian J Obs Gynae Pract 2002;16:3-11.

4. Diplock AT. Antioxidant nutrients and disease prevention: An overview. Am J Clin Nutr 1991:53:189S-193S

5. Halliwell B, Gutteridge JM. Free Radicals in Biology and Medicines. $3^{\text {rd }}$ ed. UK: Oxford Science Publications; 1990. p. 192.

6. Rajneesh CP, Manimaran A, Sasikala KR, Adaikappan P. Lipid peroxidation and antioxidant status in patients with breast cancer. Singapore Med J 2008;49:640-3.

7. Lopaczynski W, Zeisel SH. Antioxidants: Automatic cell death. Cancer Nutr Res 2001;21:295-307.

8. Parola M, Leonarduzzi G, Robino G, Albano E, Poli G, Dianzani MU, et al. On the role of lipid peroxidation in the pathogenesis of liver damage induced by long-standing cholestasis. Free Radic Biol Med 1996;20:351-9.

9. Yagi K. Lipid peroxides and human diseases. Chem Phys Lipids 1987;45:337-51.

10. Kakkar P, Das B, Viswanathan PN. A modified spectrophotometric assay of superoxide dismutase. Indian J Biochem Biophys 1984;21:130-2.

11. Sinha AK. Colorimetric assay of catalase. Anal Biochem 1972;47:389-94.

12. Fink R, Clemens MR, Dormandy TL. Increased free radical activity in Alcoholics. Lancet 1985;2:291.

13. Lecomte E, Herberth B, Pirollet P, Chancerelle Y, Arnaud J. Effect of alcohol consumption on blood antioxidant nutrients and oxidative stress indicators. Am J Clin Nutr 1994;60:255.

14. Singh G. Assessment of Nephrotoxicity in Health and Diseases with Special Reference to Environment. Udaipur: Ph. D Thesis Submitted to MLS University; 1997.

15. Green EL, Paller SM. Oxy free radicals in acute renal failure. Miner Electrolyte Metab 1991;17:124.

16. Jacob RA, Burri BJ. Oxidative damage and defense. Am J Clin Nutr 1996;163:985.

17. Esra B, Umit MS, Cansin S, Serpil E, Omer K. Oxidative stress and antioxidant defense. World Allergy Organ J 2012;5:9-19.

18. Malgorzata N, Andrzej G. The role of the reactive oxygen species and oxidative stress in the pathomechanism of age related ocular disease and other pathologies of anterior and posterior eye segments in adults. Oxid Med Cell Longev 2016;2016:3164734.

19. Santos JM, Tewari S, Goldberg AF, Kowluru RA. Mitochondrial biogenesis and the development of diabetic retinopathy. Free Radic Biol Med 2011;51:1849-60.

20. Stadtman ER. Role of oxidant species in aging. Curr Med Chem 2004;11:1105-12.

21. Tung KH, Wilkens LR, Wu AH, McDuffie K, Hankin JH, Nomura AM, et al. Association of dietary Vitamin A, carotenoids, and other antioxidants with the risk of ovarian cancer. Cancer Epidemiol Biomarkers Prev 2005; 143:669-76.

22. Kurahashi N, Inoue M, Iwasaki M, Tanaka Y, Mizokami M, Tsugane S. Vegetable, fruit and antioxidant nutrient consumption and subsequent risk of hepatocellular carcinoma: A prospective cohort study in Japan. Br J Cancer 2009;100:181-4. 